\title{
Short fibre elastomer composites: effect of fibre length, orientation, loading and bonding agent ${ }^{\dagger}$
}

\author{
R PRASANTHA KUMAR and SABU THOMAS* \\ School of Chemical Sciences, Mahatma Gandhi University, Priyadarshini Hills P.O., \\ Kottayam 686560 , India.
}

\begin{abstract}
A series of short fibre reinforced styrene butadiene rubber (SBR) composites were prepared by incorporating sisal fibres of different lengths and different concentrations. The vulcanization behaviour and the properties of the vulcanizates were measured by the relevant ASTM procedures. The processing characteristics such as green strength and mill shrinkage were improved by the addition of fibres. The properties like tensile strength, tear strength, moduli at $10 \%$ and $20 \%$ elongations were found to be maximum for composites containing longitudinally oriented fibres of length $6 \mathrm{~mm}$. Mixes containing $35 \mathrm{phr}$ loading of fibres and bonding agent showed better mechanical performance than others. The failure behaviour of tensile and tear specimens have been analysed by scanning electron microscopy techniques.
\end{abstract}

Keywords. Sisal fibre; styrene butadiene rubber (SBR); fibre length; fibre orientation; interfacial bond strength; bonding agent.

\section{Introduction}

Short fibres are used in rubber compounding due to the considerable processing advantages, improvement in certain mechanical properties and for economic considerations (Derringer 1971). The reinforcement of an elastomer with short fibres combine the elasticity of the rubber matrix with the strength and stiffness of the fibre. The most important parameters which affect the short fibre reinforcement are fibre aspect ratio, fibre orientation and adhesion between the fibre and the matrix.

The natural and synthetic fibres can be easily incorporated into the elastomer matrices. Short fibre elastomer composites containing natural fibres have gained much importance due to their renewable nature, low cost and amenability to chemical and mechanical modification. A considerable amount of research work has been done in the field of short fibre elastomer composites (Beatty and Hamed 1978; Goettler et al 1981; Rogers 1981). These composites show anisotropy in mechanical properties (Coran et al 1974). Some researchers have carried out systematic studies on short jute fibre reinforced natural rubber (NR), carboxylated nitrile rubber (XNBR) and SBR composites (Chakraborty et al 1982; Setua and De 1983; Murthy and De 1984).

The present work deals with short sisal fibre reinforced styrene butadiene rubber composites. The intent of this publication is to report the mechanical properties of SBR composites, giving special reference to the effect of fibre length, fibre orientation, fibre loading, and the bonding agent.

\footnotetext{
'Paper presented at the poster session of MRSI AGM VI, Kharagpur, 1995

*To whom all correspondence should be addressed.
} 


\section{Experimental}

\section{$2.1 \quad$ Materials}

Sisal fibre which is used for the experiment is provided by a local processing unit. It is reported that sisal fibres contain cellulose $78 \%$, hemicellulose and pectins $10 \%$, lignin $8 \%$, waxes $2 \%$ and ashes $1 \%$ (Barkkakaty 1976). Styrene butadiene rubber (SBR-1502) synthesized in the trade name of synaprene, was obtained from the Synthetics and Chemicals, Bareilly, UP. The bonding agent consisting of hexa and resorcinol used were of laboratory reagent grade. All other additives used were of commercial grade. The compounding was done based on a basic test recipe as shown in table 1.

\subsection{Composites preparation}

The composites were prepared by incorporating short sisal fibres of different lengths, viz. Gum (mix A), $2 \mathrm{~mm}(\mathrm{~B}), 6 \mathrm{~mm}(\mathrm{C})$ and $10 \mathrm{~mm}$ (D) and different concentrations, viz. $5 \mathrm{phr}(\mathrm{E}), 10 \mathrm{phr}(\mathrm{F}), 15 \mathrm{phr}(\mathrm{G}), 20 \mathrm{phr}(\mathrm{H})$ and $35 \mathrm{phr}+$ bonding agent $(\mathrm{L})$ into the styrene butadiene rubber matrix. All mixes were prepared by means of a two-roll laboratory mixing mill. The curing characteristics were studied by a Monsanto Rheometer R-100. The samples were vulcanized at $150^{\circ} \mathrm{C}$ in an hydraulic press to their respective cure times, as obtained from rheographs.

Table 1. Compound formulation.

\begin{tabular}{lc}
\hline Components & $\left(\right.$ phr $\left.^{*}\right)$ \\
\hline SBR - 1502 & 100 \\
Sulphur & $2 \cdot 2$ \\
Stearic acid & 2 \\
Zinc oxide & 5 \\
Resorcinol & 5 \\
Hexa & $2 \cdot 5$ \\
CBS $^{\mathrm{b}}$ & 1 \\
TDQ & 1 \\
Sisal fibre & Variable \\
(Fibre length and loading) & \\
\hline
\end{tabular}

* Parts per hundred rubber; ${ }^{a}$ Hexamethylene tetramine; ${ }^{b} \mathrm{~N}$-cyclohexyl benzothiazole sulphenamide; ${ }^{\mathrm{c}} 2,2,4$ Trimethyl 1,2-dihydro quinoline polymerized.

Table 2. Processing characteristics.

\begin{tabular}{lcccc}
\hline Mixes & $T_{\max }(\mathrm{dNm})$ & $T_{\min }(\mathrm{dNm})$ & $t_{90}(\mathrm{~min})$ & $\begin{array}{c}\text { Scorch time } \\
(\min )\end{array}$ \\
\hline A & 56 & 8.9 & $29 \cdot 15$ & 14 \\
B & 61 & 13 & 14 & $6 \cdot 5$ \\
C & 81 & $16 \cdot 10$ & $17 \cdot 15$ & $6 \cdot 25$ \\
D & 70.5 & $11 \cdot 25$ & $18 \cdot 15$ & 10 \\
L & 97 & $19 \cdot 50$ & 6.05 & 1
\end{tabular}


The tensile and tear samples were tested as per relevant ASTM procedures in a universal testing machine (ZWICK 1474) at a cross head speed of $50 \mathrm{~cm} \mathrm{~min}^{-1}$ along and across the grain direction. Resilience and hardness measurements were also made at room temperature. The SEM studies of composites were carried out using JEOL scanning electron microscope model JSM-35C.

\section{Results and discussion}

\subsection{Processing characteristics}

From table 2, it is found that the addition of fibres increases torque value of the SBR compound. The minimum torque value is shown due to the softening of the rubber matrix. Due to the crosslinking of the rubber, the value of the torque shows a rapid increase from its minimum value. The maximum torque $\left(T_{\max }\right)$ increases with increase in fibre content. The optimum cure time $\left(t_{90}\right)$ is also found to decrease with the addition of fibres and bonding agent.

\subsection{Fibre length}

The properties of short fibre elastomer composites depend on the degree to which an applied load is transmitted to the fibres. The extent of load transmittance is a function

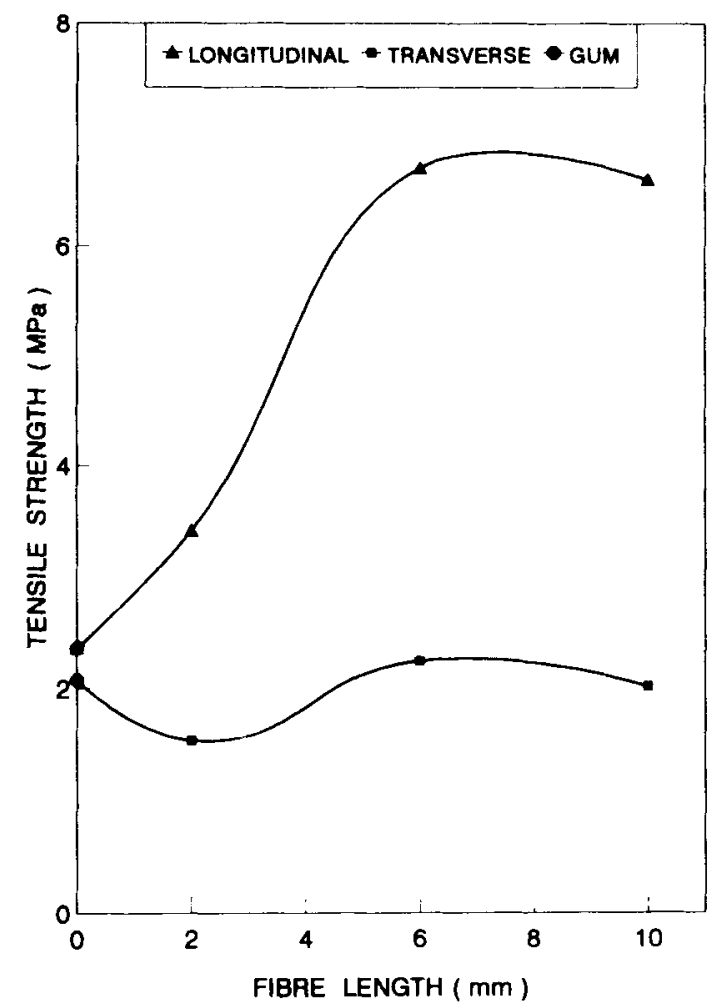

Figure 1. Effect of fibre length and orientation on tensile strength of composites. 
Table 3. Properties of mixes (Variable fibre length).

\begin{tabular}{|c|c|c|c|c|c|c|}
\hline \multirow{3}{*}{$\begin{array}{l}\text { Mixes } \\
\text { SBR } \\
\text { gum }\end{array}$} & \multirow{3}{*}{$\begin{array}{c}\begin{array}{c}\text { Fibre } \\
\text { length } \\
(\mathrm{mm})\end{array} \\
-\end{array}$} & \multirow{2}{*}{$\frac{\begin{array}{c}\text { Orien- } \\
\text { tation* }\end{array}}{\mathrm{L}}$} & $\begin{array}{c}\text { Modu } \\
10 \% \\
\text { elor }\end{array}$ & $\begin{array}{l}\text { (PPa) } \\
20 \% \\
\text { ion }\end{array}$ & \multirow{2}{*}{$\begin{array}{c}\begin{array}{c}\text { Elongation } \\
\text { at break } \\
(\%)\end{array} \\
373\end{array}$} & \multirow{2}{*}{$\begin{array}{c}\begin{array}{c}\text { Tear } \\
\text { strength } \\
(\mathrm{MPa})\end{array} \\
13.89\end{array}$} \\
\hline & & & 0.375 & 0.53 & & \\
\hline & & $\mathrm{T}$ & $0 \cdot 360$ & 0.50 & 288 & 9.94 \\
\hline $\mathrm{SBR}+$ & 2 & $\mathrm{~L}$ & 2.960 & 3.296 & 24 & $25 \cdot 37$ \\
\hline $\begin{array}{l}35 \mathrm{phr} \\
\text { sisal } \\
\text { fibre }\end{array}$ & & $\mathrm{T}$ & 0.942 & 1.295 & 66 & 18.48 \\
\hline \multirow[t]{2}{*}{$"$} & 6 & $\mathbf{L}$ & $5 \cdot 700$ & $6 \cdot 380$ & 23 & $46 \cdot 50$ \\
\hline & & $T$ & $1 \cdot 220$ & 1.750 & 69 & $23 \cdot 30$ \\
\hline \multirow[t]{2}{*}{$"$} & 10 & $\mathbf{L}$ & $5 \cdot 440$ & 6.550 & 21 & $39 \cdot 50$ \\
\hline & & $\mathrm{T}$ & $1 \cdot 240$ & 1.730 & 51 & $25 \cdot 03$ \\
\hline
\end{tabular}

${ }^{*}$ L, Longitudinal; $T$, transverse.

of fibre length and magnitude of fibre-matrix interfacial bond. In these composites, there exists a critical fibre length that is required for the fibre to develop its fully stressed condition in the matrix. If critical fibre length $\left(l_{\mathrm{c}}\right)$ is greater than the length of the fibre, the stressed fibre will debond from the matrix and the composite will fail at low load. If $l_{c}$ is less than the length of the fibre, the stressed composite will lead to breaking of fibres.

The tensile strength of the composite can be explained on the basis of fibre length and orientation. The tensile strength shows a rapid increase up to $6 \mathrm{~mm}$ and decreases gradually in both fibre orientations. However, a slight decrease in tensile strength is shown in the transverse orientation at $2 \mathrm{~mm}$ fibre length. The tensile strength of the composites depends on the fibres which obstruct the progress of the fructure front. Breakage and pulling out of the fibres take place when the fibres are oriented longitudinally, whereas for transverse orientation, the crack progresses in the direction of fibre alignment, experiencing a lower resistance by the fibres. Hence, tensile strength of composites with longitudinal fibre orientation is always higher than that of composites with transverse fibre orientation (see figure 1).

The effect of fibre length and orientation on tear strength, is given in table 3 . In both orientations, the tear strength shows a maximum value at $6 \mathrm{~mm}$ fibre length. The increase in tear strength is due to the obstruction caused to the tear path by the short fibres. The interfacial interaction between the rubber matrix and fibre reaches a maximum value when the fibre length is $6 \mathrm{~mm}$ and the effect of fibre length disappears with longer fibres because of fibre entanglement and breakage. At higher fibre lengths, dispersion of fibres in the rubber matrix becomes very difficult. The increase in fibre length causes fibre to fibre interactions. Hence a further increase in fibre length after $6 \mathrm{~mm}$ decreases the tensile and tear strengths of the composites.

\subsection{Fibre orientation}

In the case of short fibre reinforced elastomer composites, two modes of orientations are possible here: (i) longitudinal orientation i.e. fibres are aligned along the grain direction and (ii) transverse orientation i.e. fibres are aligned across the grain direction. 


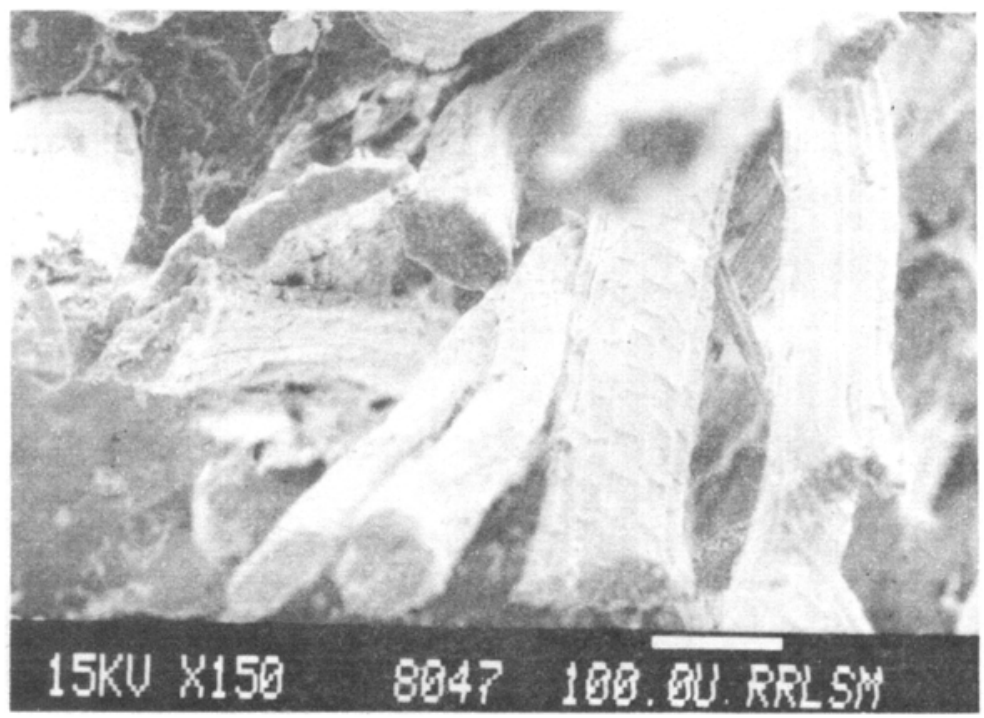

Figure 2. SEM photograph showing longitudinal orientation of fibres.

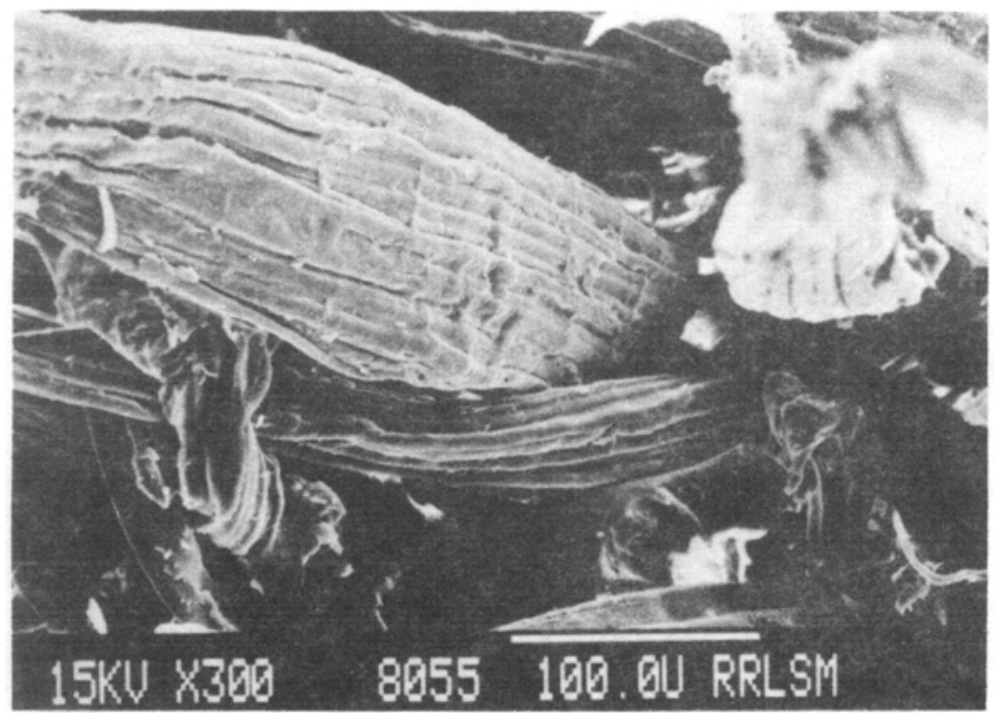

Figure 3. SEM photograph showing transverse orientation of fibres.

On examining the fracture surfaces of tensile and tear samples, the fibre orientation in the composites can be analysed. The longitudinal and transverse fibre orientations in the samples are shown in the SEM photographs (see figures 2 and 3). The broken fibre ends protruded from the fracture surface indicate the longitudinal orientation while in the case of transverse orientation the fibres are aligned across the direction of the applied force. 


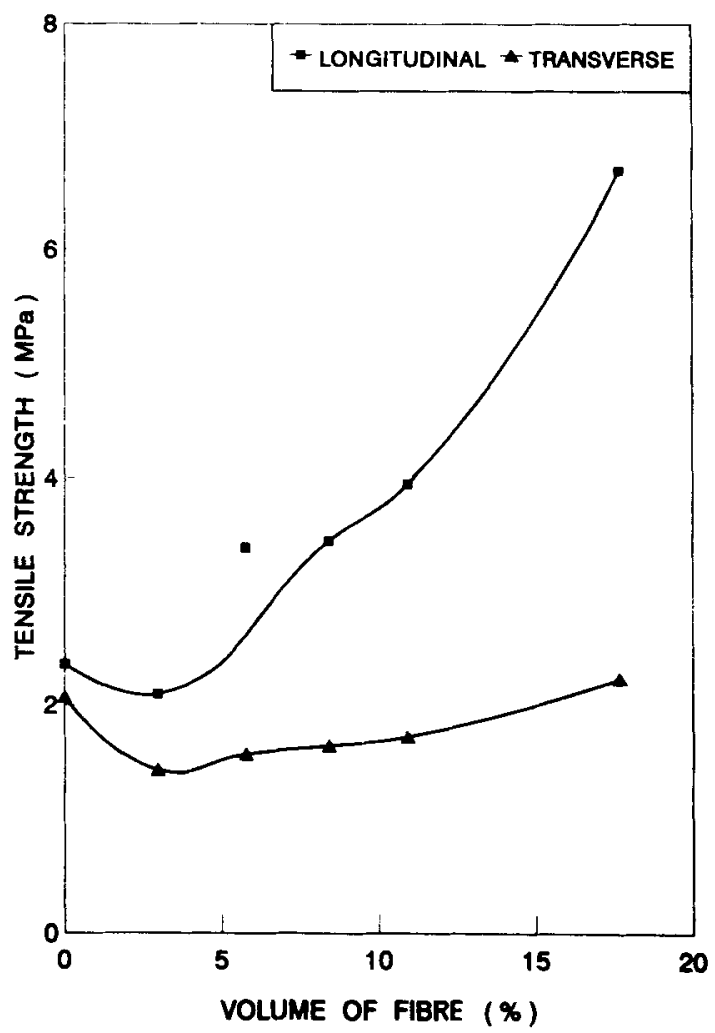

Figure 4. Effect of fibre loading and orientation on tensile strength of composites.

Table 4. Properties of mixes (Variable loading).

\begin{tabular}{cccccccc}
\hline & & \multicolumn{7}{c}{ Mixes } \\
\cline { 3 - 7 } Properties & $\begin{array}{c}\text { Orien- } \\
\text { tation* }\end{array}$ & A & E & F & G & H & C \\
\hline Modulus(MPa). & & & & & & & \\
$10 \%$ elongation & $\mathrm{L}$ & 0.37 & 0.93 & 2.07 & 2.45 & 3.20 & 6.03 \\
& T & 0.36 & 0.45 & 0.54 & 0.70 & 0.85 & 1.22 \\
$20 \%$ elongation & $\mathrm{L}$ & 0.53 & 1.45 & 3.03 & 3.25 & 3.91 & 6.66 \\
& $\mathrm{~T}$ & 0.50 & 0.64 & 0.79 & 1.02 & 1.42 & 1.75 \\
Elongation at & $\mathrm{L}$ & 400 & 80 & 40 & 30 & 27 & 23 \\
break (\%) & $\mathrm{T}$ & 288 & 221 & 180 & 126 & 81 & 69 \\
Tear strength & $\mathrm{L}$ & 13.8 & 19.1 & 21.1 & 26.8 & 28.1 & 46.5 \\
$(\mathrm{kN} / \mathrm{m})$ & $\mathrm{T}$ & 9.9 & 14.9 & 16.7 & 17.9 & 19.1 & 23.3 \\
\hline
\end{tabular}

${ }^{*} \mathrm{~L}$, Longitudinal; T, transverse.

\subsection{Fibre content}

The strength of the unfilled SBR matrix is poor due to the non-crystallizing nature of this elastomer. Hence, the presence of even a small fraction of fibre increases its 


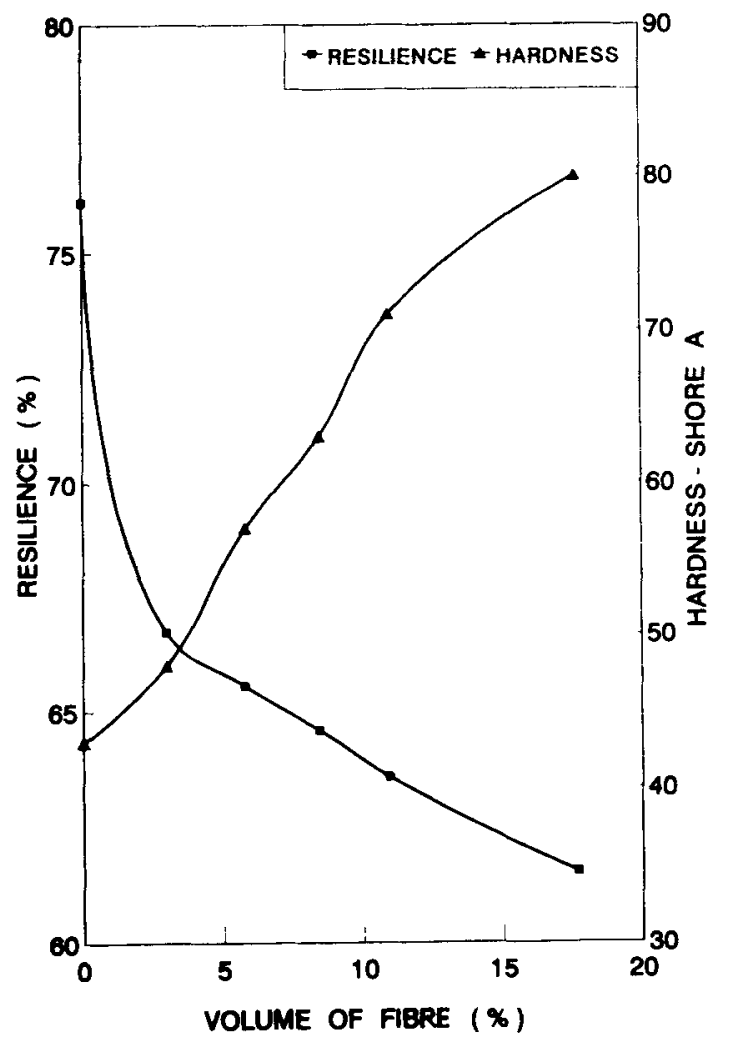

Figure 5. Effect of fibre loading on resilience and hardness of composites.

overall strength of the non-strain hardening SBR. Thus the strength of the composite increases abruptly to a value which is about 3 times greater than that of the gum. The tensile strength can be explained on the basis of orientation and concentration of fibres (see figure 4). It is found that the tensile strength in the longitudinal direction increases with increase in fibre concentration. The tensile strength continuously increases on further increase in loading of fibres. At low fibre concentration, the fibre acts as flaw in the rubber matrix. As the fibre concentration increases from $5 \mathrm{phr}$ to $35 \mathrm{phr}$, the stress is more evenly distributed and strength of the composite increases. Above 35 phr loading, the incorporation of fibres into SBR matrix was difficult due to the entanglement of fibres and the breakage of fibres occurred during mixing operations. But in transverse orientation, no such improvement in tensile strength was shown upon the addition of short fibres.

The mechanical properties such as modulus, tear strength and hardness were found to increase with fibre loading while elongation at break and resilience showed a decreasing trend (see table 4 and figure 5).

\subsection{Bonding agent}

Further increase in tensile strength is seen on the incorporation of bonding agent to the system. The increase in maximum torque is attributed to the formation of strong 
Table 5. Properties of mixes (Bonding agent).

\begin{tabular}{|c|c|c|c|c|}
\hline \multirow[b]{2}{*}{ Properties } & \multirow{2}{*}{$\begin{array}{l}\text { Orien- } \\
\text { tation* }\end{array}$} & \multicolumn{3}{|c|}{ Mixes } \\
\hline & & A & $\mathrm{C}$ & $\mathrm{L}$ \\
\hline \multirow[t]{2}{*}{ Tensile strength $(\mathrm{MPa})$} & $\mathrm{L}$ & $2 \cdot 36$ & 6.70 & $8 \cdot 10$ \\
\hline & $\mathrm{T}$ & $2 \cdot 07$ & $2 \cdot 24$ & $2 \cdot 30$ \\
\hline \multirow[t]{2}{*}{ Elongation at break $(\%)$} & $\mathrm{L}$ & 373 & 23 & 15 \\
\hline & $\mathrm{T}$ & 288 & 69 & 65 \\
\hline \multirow[t]{2}{*}{ Tear strength $(\mathrm{kN} / \mathrm{m})$} & $\mathrm{L}$ & $13 \cdot 89$ & $46 \cdot 50$ & $56 \cdot 25$ \\
\hline & $\mathrm{T}$ & 9.94 & $23 \cdot 30$ & $36 \cdot 66$ \\
\hline \multicolumn{5}{|l|}{ Hardness } \\
\hline Shore-A & & 43 & 80 & 86 \\
\hline Resilience (\%) & & $76 \cdot 10$ & $61 \cdot 52$ & $58 \cdot 26$ \\
\hline
\end{tabular}

${ }^{*}$ L, Longitudinal; $T$, transverse.

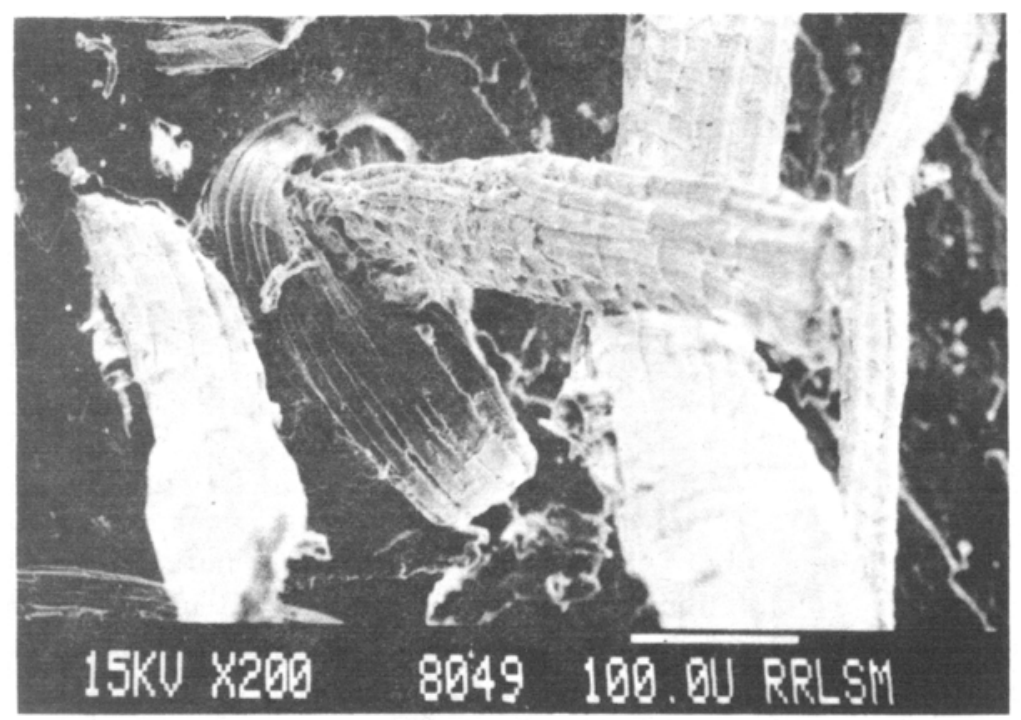

Figure 6. SEM photograph showing the interfacial adhesion between the fibre and the rubber.

chemical bonds with the sisal fibre and SBR matrix due to the presence of bonding agent. The optimum cure time is also found to decrease drastically with the addition of fibre and bonding agent.

The properties like tensile strength, tear strength, hardness, etc were found to increase with the addition of bonding agent with the untreated fibres (see table 5). Hexa-resorcinol system enhanced the binding strength more significantly.

The SEM studies revealed the indications of high interfacial adhesion. Figure 6 shows that not so many holes were left after the fibres were pulled out from the SBR matrix. It shows a better adhesion between the fibres and matrix due to the addition of bonding agent. 


\section{Conclusions}

Natural cellulosic fibres like sisal fibres, having a length of $6 \mathrm{~mm}$ can be effectively used as good reinforcement in styrene butadiene rubber matrix. The longitudinally oriented fibre composites showed better physical and mechanical properties than those in transverse oriented ones. The maximum amount of fibres that can be incorporated in to the SBR matrix were found to be $17.7 \%$. SEM studies revealed that the use of bonding agent for the reinforcement of rubber by untreated sisal fibres resulted in vulcanizates with very good physical and mechanical properties. Composites containing the bonding agent and $35 \mathrm{phr}$ loading of sisal fibres showed better interfacial bond strength.

\section{Acknowledgement}

One of the authors (RPK) is grateful to the Council of Scientific and Industrial Research, New Delhi, for financial assistance in the form of a Fellowship.

\section{References}

Barkkakaty B C 1976 J. Appl. Polym. Sci. 202921

Beatty J R and Hamed P 1978 Elastomeric's 27110

Chakraborty S K, Setua D K and De S K 1982 Ruhber Chem. Technol. 551286

Coran A Y, Boustany K and Hamed P 1974 Rubber Chem. Technol. 47396

Derringer D C 1971 Rubber World 45165

Goettler L A, Lambright A J, Leib R I and Dimauro P J 1981 Rihber Chem. Tedhnol. 54274

Murthy V M and De S K 1984 J. Appl. Polym. Sci. 291355

Rogers J W 1981 Rubber World 27183

Setua D K and De S K 1983 Ruhber Chem. Technol. 56808 